\title{
A Study About Some Mechanical Properties for Composites Reinforced with Corn Cob Powder
}

\author{
COSMIN MIHAI MIRITOIU ${ }^{1}$, MARIUS MARINEL STANESCU ${ }^{*}$, DUMITRU BOLCU ${ }^{1}$, \\ ALEXANDRU IOAN RADOI ${ }^{1}$, CLAUDIU NICOLICESCU ${ }^{2}$, ALIN DINITA ${ }^{3}$ \\ ${ }^{1}$ University of Craiova, Faculty of Mechanics, 107 Calea Bucuresti, 200512, Craiova, Romania \\ ${ }^{2}$ University of Craiova, Faculty of Mechanics, 1 Calugareni Str., 220037, Drobeta Turnu Severin, Romania \\ ${ }^{3}$ University of Petrolium-Gas, Faculty of Mechanical and Electrical Engineering, 39 Bucuresti, 100680, Ploiesti, Romania
}

\begin{abstract}
In this paper we have created some composites reinforced with corn cob powder and the matrix was made by a combination between Resoltech 1050 resin with its Resoltech 1058 hardener. For the composites manufacturing, we have used the manual casting technique. For the new manufactured composites, we have determined the mechanical properties from the tensile test according to ASTM D3039: Young modulus, breaking strength and elongation at break. We have also molded samples for the compression test according to ASTM D695-15 and we have determined the breaking strength. The tensile and compression tests were made on universal testing machines. In the end, we have determined also the dynamic mechanical properties for the studied material by clamping the samples at one edge and leaving the samples unconstrained at the other edge. At the unconstrained edge we have placed a Bruel\&Kjaer accelerometer which recorded the samples free vibrations. From the free vibrations recording and Euler-Bernoulli theory, we have determined the next dynamic mechanical properties: damping factor per unit mass and length, eigenfrequency, dynamic modulus of elasticity, loss factor and dynamic rigidity. From the experimental results, we have obtained increased breaking strength values for the proposed material at compression compared to the tensile test. Compared to similar materials studied in the engineering literature, we have obtained increased compression breaking strength.
\end{abstract}

Keywords: epoxy resin, corn cob, powder, vibrations, tensile, compression

\section{Introduction}

The corn cob is a solution to reinforce composite materials [1-4]. In [4] there were used samples with corn cob powder, E-glass and epoxy resin. From the tensile test, there were obtained values between 14..18 MPa for the breakıng stress and $650 . .900$ for the modulus of elasticity. From the bending test, values between 27 and $37 \mathrm{MPa}$ for the breaking stress and between 3200 up to 4600 for the modulus of elasticity were obtained. Lignosulfonates or sulfonated lignin are water-soluble polyelectrolytic polymers which are obtained from lignin, a polymer from phenylopropane units. They are by-products of the wood pulp production using sulphite pulp [5]. The sulphite pulp refers to wood chips that are treated with sulphite and bisulphite ions solutions. In [6], some composites with lignosulphonate matrix and corn cob powder were built. There were used particles sizes between 0.090 and $1.8 \mathrm{~mm}$ and reinforcement proportion between 10 and 35\%. There were obtained maximum values for the compression breaking strength of $20 \mathrm{MPa}$ and $320 \mathrm{MPa}$ for the Young modulus.

There were made researches for integrating the corn stalk in civil constructions. In this way, in [7], there are presented researches regarding inserting the corn stalks in building isolation combined with cement from magnesium phosphate. The mixture between those parts fulfill the conditions for being used in civil contructions.

In [8], some green composite materials were made using the thermoplastic matrix of corn starch and fibers from corn husk. Those corn husk fibers were used as a filler. The materials were manufactured by a molding method using different proportions of husk fiber (between 0-8\%) and fructose as a plasticizer at a fixed amount of $1 / 4$ for the corn starch weight. The physical, thermal, morphological and tensile

*email: mamas1967@gmail.com 
characteristics of composites were investigated. Values between 6 and $13 \mathrm{MPa}$ for the breaking stress, 90 and $650 \mathrm{MPa}$ for the modulus of elasticity and 2.5 and $7 \%$ elongation at break values.

The research from [9] deals with the investigation for corn starch by using a X-ray diffraction technique and thermal analysis. There was also investigated the manufacturing and characterization for starch fiber composites - banana and sugar cane. The thermal analysis has shown a good thermal stability for the composites manufacturing. There were also determined some mechanical characteristics from the tensile test: Young modulus between 24.6 and $468.2 \mathrm{MPa}$, breaking stress between 1.7 and 4MPa, elongation at break between 2.7 and $75.5 \%$.

In this paper we have manufactured some composite materials from corn cob powder as a reinforcement and the epoxy resin as a matrix. The corn was brought in a powder shape by using a classic mill.

\section{Materials and methods}

In this research we have obtained some composite materials by using the con cob powder as reinforcement and the epoxy resin RESOLTECH 1050 with the hardener RESOLTECH 1058. The resin mechanical properties can be found in [10].

\subsection{Tensile test}

For the tensile test, we have manufactured, by manual casting, a plate with the dimensions of $420 \times 297 \mathrm{~mm}$. The plate had a thickness of $8 \mathrm{~mm}$. We have used a proportion of $65 \%$ corn stalk powder and 35\% epoxy resin. From this plate we cut ten samples for the tensile test. Some of the samples used in this test are presented in Figure 2, with the dimensions $200 \times 25 \times 8 \mathrm{~mm}$. We have used the standard ASTM D3039 for the tensile test [11].

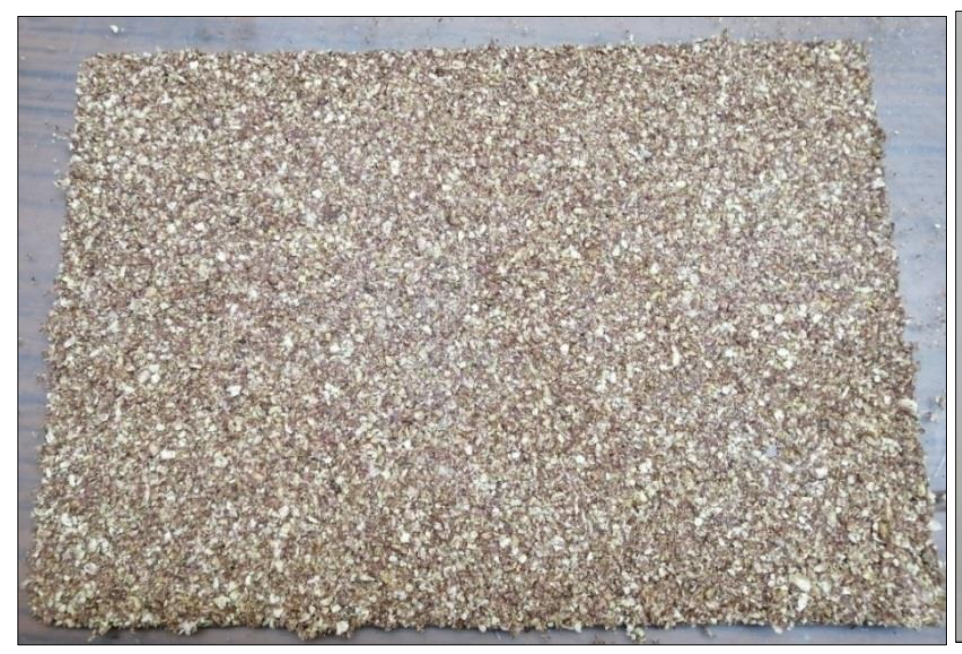

Figure 1. The plate obtained from the manual casting

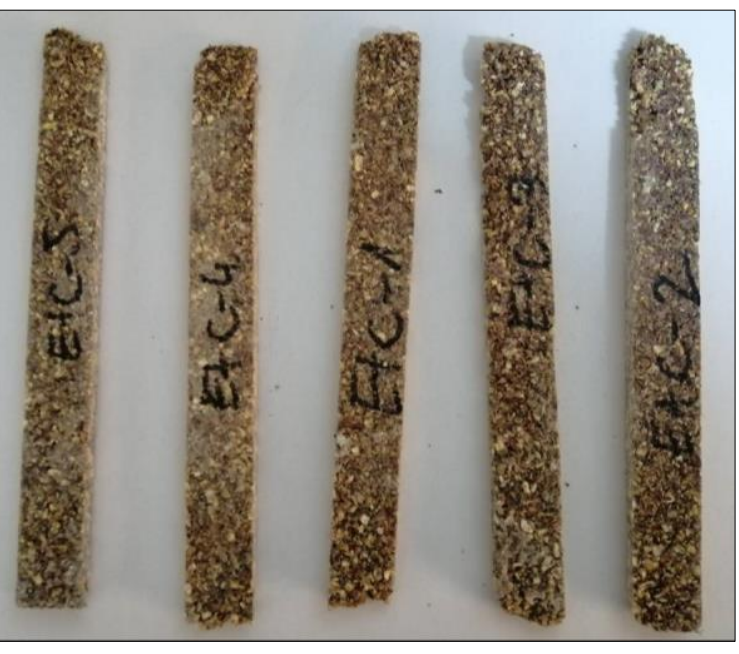

Figure 2. Some samples used for the tensile test

\subsection{Compression test}

We have chosen to test the proposed material to compression because we have assumed that the studied material could have a behaviour similar to the concrete: a low tensile strength compared to the compression one. For this test, we have used the next proportions: $50 \%, 65 \%$ and $75 \%$ corn cob powder and $50 \%, 35 \%$ and $25 \%$ epoxy resin respectively. We have used the standard ASTM D695-15 for the compression test [12]. The samples dimensions were $\Phi 30 \times 60 \mathrm{~mm}$ with cylindrical shape and there were casted ten samples from each proportion reinforcement - matrix cathegory. An example with the samples used for the compression test having 50\% epoxy resin and 50\% corn cob powder is presented in Figure 3. 


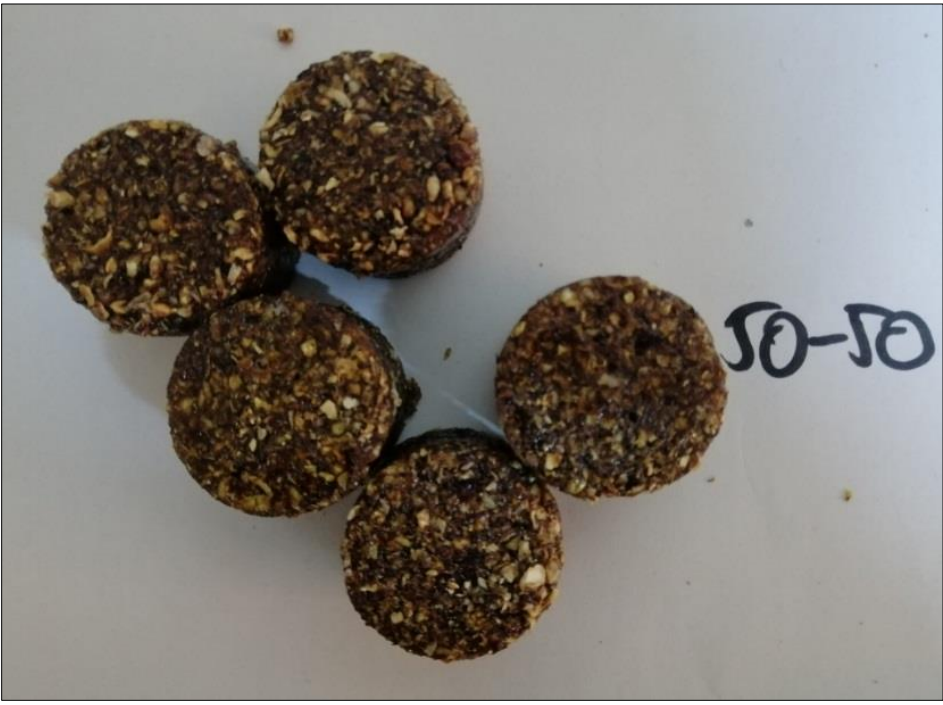

Figure 3. Some samples used for the compression test, with $50 \%$ corn cob powder

\subsection{Vibrations tests}

We have determined some mechanical parameters through the vibrations test, such as: the damping factor reported to the unit mass and length, the eigenfrequency, the dynamic modulus of elasticity, the dynamic rigidity and the loss factor for some with 65-35 reinforcement-matrix ratio. The bars were embedded at one end with a jaw vise on a rigid table, each bars having 100, 120, 140, 160 and $180 \mathrm{~mm}$ free lengths. We have tested ten samples for each free length. On the free end, at about $5 \mathrm{~mm}$ from the edge, on the longitudinal axis, the Bruel\&Kjaer accelerometer was glued by wax on the sample. For each assembly condition of the bars type and free length, an initial displacement was applied to the bar and then, by releasing, the bar performed free damped vibrations. To study the vibrations, the next equipment was used: an accelerometer Bruel\&Kjaer that had the sensitivity $4 / 1000 \mathrm{pC} / \mathrm{ms}^{-2}$ connected to a signal amplifier NEXUS 2692-A-0I4 which was connected with a data acquisition system SPIDER 8. The SPIDER 8 apparatus was connected by USB with a laptop. The link between the two entities is made through CATMAN EASY software.

From the free vibrations experimental recording in a certain point, we can determine the damping factors related to unit mass and length by using the relationships (1) and (2) [13].

$$
\begin{gathered}
\mu=\frac{1}{t_{2}-t_{1}} \ln \frac{v_{1}}{v_{2}} \\
C=\frac{2}{t_{2}-t_{1}} \ln \frac{v_{1}}{v_{2}}\langle\rho A\rangle
\end{gathered}
$$

In (1) and (2) we have marked with $t_{1}$ and $t_{2}$ the time values for two peaks in the free vibrations diagram; $v_{1}$ is the amplitude maximum value that corresponds to $t_{1}$ time and $v_{2}$ is the amplitude maximum value that corresponds to $t_{2}$ time; $\langle\rho A\rangle$ is the specific mass.

The other experimental values are determined with (3), (4) and (5) according to [13].

$$
\begin{gathered}
\eta=\frac{\mu}{\pi \cdot v} \\
E=\frac{12 \cdot \rho \cdot l^{4} \cdot v^{2}}{\lambda^{2} \cdot t^{2}}
\end{gathered}
$$




$$
E I=\frac{4 \cdot \pi^{2} \cdot \rho \cdot A \cdot l^{4} \cdot v^{2}}{\zeta^{2}}
$$

In (3), (4) and (5) are presented the next mechanical parameters: $v$ the eigenfrequency, 1 the sample free length, $\lambda$ a constant from the samples fixing condition (0.5596 for our case, [14]), $t$ is the sample thickness, $\zeta$ a constant from the samples fixing condition (0.5596 for our case, [15]).

\section{Results and discussions}

In the next paragraphs we have denoted as a representative sample, the sample for which the obtained mechanical properties values are the closest to the arithmetic mean value of the determined mechanical characteristic, for the whole set of samples of that type.

\subsection{Tensile test}

In the Figure 4 we present the Hooke graphic for a representative sample which is tensile tested. All the experimental results are written in Table 1.

Table 1. Tensile tests results

\begin{tabular}{|c|c|c|c|}
\hline \multirow{2}{*}{ Corn cob powder + epoxy resin } & \multicolumn{3}{|c|}{ Characteristics } \\
\cline { 2 - 4 } & $\begin{array}{c}\text { Modulus of elasticity } \\
(\mathrm{MPa})\end{array}$ & $\begin{array}{c}\text { Breaking strength } \\
(\mathrm{MPa})\end{array}$ & $\begin{array}{c}\text { Elongation at break } \\
(\%)\end{array}$ \\
\hline Value & $193 \pm 42$ & $6 \pm 1$ & $1.6 \pm 0.2$ \\
\hline
\end{tabular}

From the Table 1 we can see that our proposed material has low tensile mechanical properties. In [8] there were obtained also low tensile mechanical properties for similar materials, but higher than the ones studied in this research.

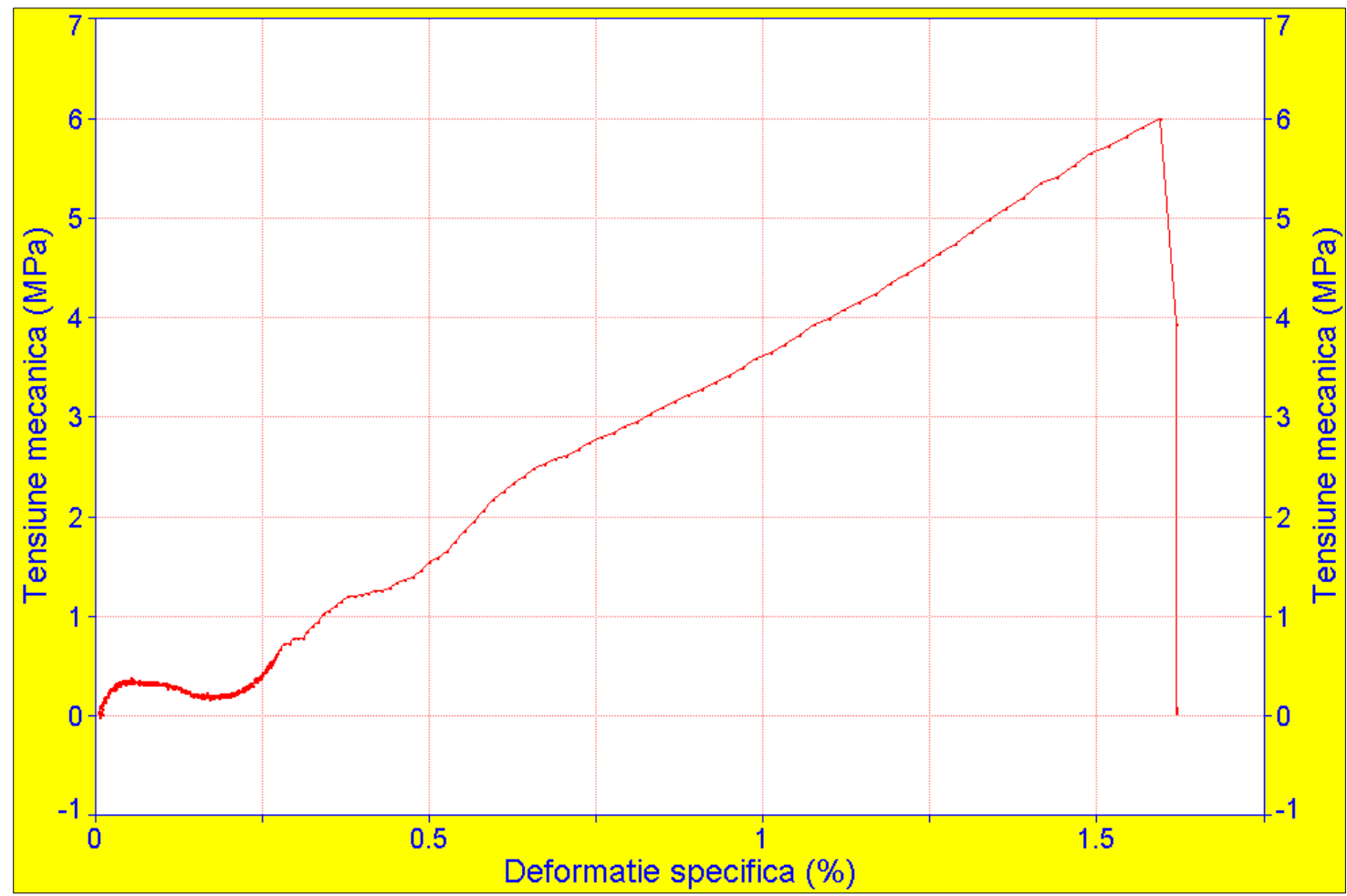

Figure 4. The Hooke graphic for a representative sample, tensile tested 


\subsection{Compression test}

In the Figure 5 we present the Hooke graphic for a representative sample tested for compression, with the ratio between the reinforcement and matrix being 50-50. The compression test results are written in Table 2.

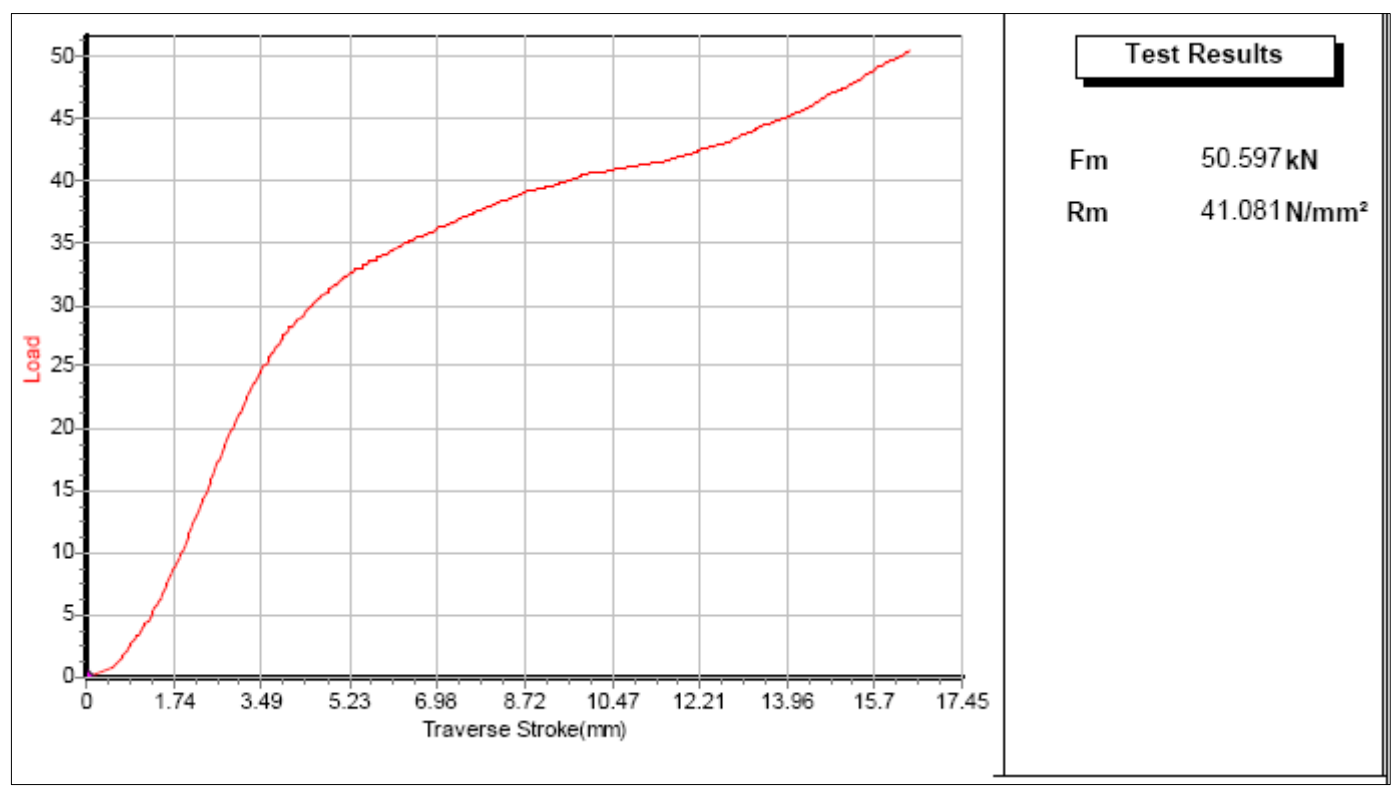

Figure 5. The Hooke graphic for a representative sample with 50-50 ratio between reinforcement and matrix, tested for compression

Table 2. Compression tests results

\begin{tabular}{|c|c|c|}
\hline \multirow{2}{*}{ Corn cob powder + epoxy resin } & \multicolumn{2}{|c|}{ Characteristic } \\
\cline { 2 - 3 } & Breaking strength $(\mathrm{MPa})$ & Maximum force $(\mathrm{kN})$ \\
\hline $50-50$ & $41 \pm 3$ & $50.6 \pm 7.4$ \\
\hline $65-35$ & $25 \pm 2.5$ & $25 \pm 7.1$ \\
\hline $75-25$ & $3 \pm 0.5$ & $3.75 \pm 0.24$ \\
\hline
\end{tabular}

From the experimental data we can see that our proposed composite has increased mechanical properties at compression compared to the tensile test. We have also obtained increased mechanical properties compared to similar samples (with the same reinforcement but another matrix) like the ones studied in [6].

\subsection{Vibrations tests}

In the Figure 6 we present the vibration recording (eigenfrequency and damping factor per unit mass determination) in the 65-35 (ratio between reinforcement and matrix) sample, for $140 \mathrm{~mm}$ free length. By inserting the experimental values (for the eigenfrequency and damping factor) in (2), (3), (4) and (5) we have determined the other dynamic mechanical characteristics, like: damping factor related to unit mass and length, loss factor, dynamic modulus of elasticity and dynamic rigidity. All the geometrical parameters and the arithmetic mean values for the dynamic mechanical parameters are written in table 3 . 
Table 3. Free vibrations results (arithmetic mean values) and geometrical characteristics of samples

\begin{tabular}{|c|c|c|c|c|c|c|c|}
\hline \multirow{3}{*}{$\begin{array}{l}\text { Corn cob powder + } \\
\text { epoxy resin }\end{array}$} & \multicolumn{7}{|c|}{ Characteristic } \\
\hline & $\begin{array}{l}\text { Free } \\
\text { length }\end{array}$ & $\begin{array}{c}\text { Damping factor } \\
\text { related to unit } \\
\text { mass }\end{array}$ & Eigenfrequency & Density & $\begin{array}{c}\text { Specific } \\
\text { mass }\end{array}$ & $\begin{array}{c}\text { Dynamic } \\
\text { Young } \\
\text { modulus }\end{array}$ & $\begin{array}{l}\text { Dynamic } \\
\text { stiffness }\end{array}$ \\
\hline & 100 & 40.21 & 141.9 & 375 & 0.075 & 607 & 0.482 \\
\hline & 120 & 25.49 & 98.45 & 375 & 0.075 & 606 & 0.481 \\
\hline & 140 & 20.83 & 72.72 & 375 & 0.075 & 613 & 0.487 \\
\hline & 160 & 17.37 & 55.42 & 375 & 0.075 & 607 & 0.482 \\
\hline & 180 & 14.56 & 43.19 & 375 & 0.075 & 590 & 0.469 \\
\hline Arithmetic mean & & & & & & 604.6 & 0.4802 \\
\hline & $\begin{array}{l}\text { Loss } \\
\text { factor }\end{array}$ & $\begin{array}{c}\text { Damping factor } \\
\text { related to unit } \\
\text { length }\end{array}$ & & & & & \\
\hline & 0.09 & 6.03 & & & & & \\
\hline & 0.082 & 3.82 & & & & & \\
\hline & 0.091 & 3.12 & & & & & \\
\hline & 0.1 & 2.60 & & & & & \\
\hline & 0.107 & 2.18 & & & & & \\
\hline
\end{tabular}

In the Table 3, we have expressed the free length in $\mathrm{mm}$, the damping factor related to unit mass in $\mathrm{Ns} / \mathrm{m} / \mathrm{kg}$, the eigenfrequency in $1 / \mathrm{s}$, the density in $\mathrm{kg} / \mathrm{m}^{3}$, the specific mass in $\mathrm{kg} / \mathrm{m}$, the dynamic modulus of elasticity in $\mathrm{MPa}$, the dynamic rigidity in $\mathrm{Nm}^{2}$ and the damping factor related to unit length in $\mathrm{Ns} / \mathrm{m} / \mathrm{m}$.

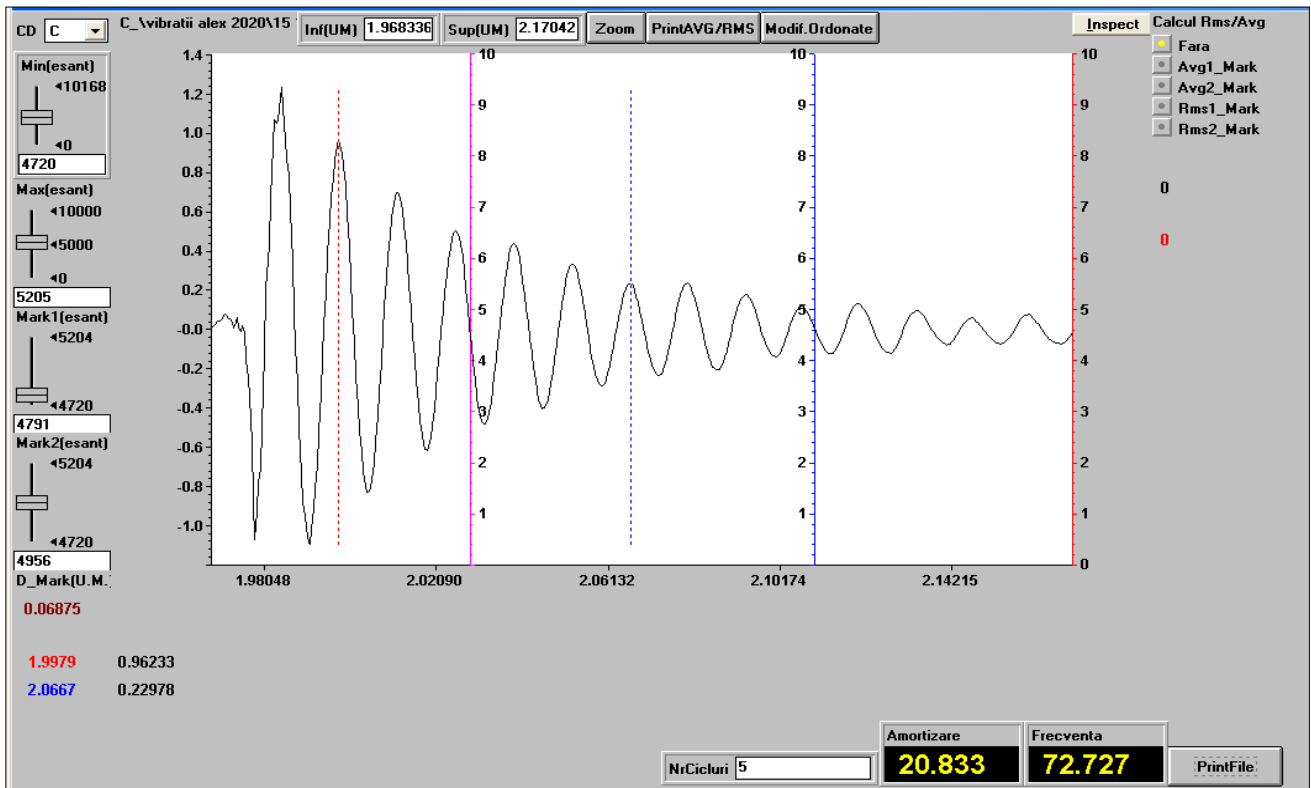

Figure 5. The vibration recording, eigenfrequency and damping factor related to unit mass determination (for the $140 \mathrm{~mm}$ free length of the sample)

\section{Conclusions}

From the experimental results, we can see that our proposed composite has different behaviour at compression compared to the tensile test, with increased mechanical properties at compression. Compared to similar composites from the previous studies, we have obtained increased mechanical properties at compression, but lower for the tensile test.

From the Table 3 where are presented the damping factor values, we can extract the next conclusions: 
these factors must be investigated for each type of bar and material and there could not be obtained a quantitative connection between the factors that affect directly or indirectly the damping phenomenon. The damping is affected by some factors, like: the bars width, thickness or free length, the specific mass, the material amount from a manufactured bar, the elastic and damping characteristics of composing materials. The bars width can affect the damping factor because it establishes the area where the air friction works on the bars.

If we make a comparison between the moduli of elasticity (static and dynamic one), we can see that the dynamic one is 3.13 times higher and the difference between their values is $68 \%$. This result is normal for composite materials because these are an-isotropic and non-homogenous. The result can be explained by the fact that the deformation from the bars free vibrations is very small because the atoms are barely moved from the equilibrium states and a small deformation leads to a high modulus of elasticity. The bars deformation in tensile test is at macro scale, so a high deformation implies a small modulus of elasticity. Also, the first derivative of the applied force with respect to atomic displacement decreases with the separation of the atoms from their mesh network. So, the atoms have an increased displacement in the tensile test which leads to the conclusion that the static modulus of elasticity must be smaller compared to the dynamic one. A similar conclusion was also obtained in the research from [16].

For their obtained mechanical properties, the composites with corn cob powder as reinforcement and epoxy resin as matrix may be used for: making almost-environment-friendly house decorations, table tops, furniture decorations or parts, replacing marble, window sills and so on.

\section{References}

1.LUO, Z., LI, P., CAI, D., CHEN, Q., QUIN, P., TAN, T., CAO, H., Comparison of performances of corn fiber plastic composites made from different parts of corn stalk, Ind. Crops. Prod., 95, 2017, 521527.

2.PANTHAPULAKKAL, S., SAIN, M., Agro-residue reinforced high-density polyethylene composites: fiber characterization and analysis of composite properties, Composites: Part A, 38, 2007, 1445-1454.

3. LUO, H., XIONG, G., MA, C., CHANG, P., YAO, F., ZHU, Y., ZHANG, C., WAN, Y., Mechanical and thermo-mechanical behaviour of sizing-treated corn fiber/polylactide composites, Polymer Testing, 39, 2014, 45-52.

4.GARADINAMI, K.R., RAJU, G.U., KODANCHA, K.G., Study on mechanical properties of corn cob particle and E-glass fiber reinforced hybrid polymer composites, Am. J. Mater. Sci., 5(3C), 2015, 86-91. 5.LEBO, S.R.Jr., GARGULAK, J.D., McNALLY, T.J., "Lignin". Kirk-Othmer encyclopedia of chemical technology, John Wiley \& Sons, 2001.

6.TRIBOT, A., DELATTRE, C., BADE, E., DUSSAP, C.-G., MICHAUD, P., de BAYNAST, H., Design of Experiments for bio-based composites with lignosulfonates matrix and corn cob fibers, Ind. Crops Prod., 123, 2018, 539-545.

7. AHMAD, M.R., CHEN, B., ODERJI, S.Y., MOHSAN, M., Development of a new bio-composite for building insulation and structural purpose using corn stalk and magnesium phosphate cement, Energy and buildings, 173, 2018, 719-733.

8.IBRAHIM, M.I.J., SAPUAN, S.M., ZAINUDIN, E.S., ZUHRI, M.Y.M, Potential of using multiscale corn husk fiber as reinforcing filler in cornstarch-based biocomposites, International Journal of Biological Macromolecules, 139, 2019, 596-604.

9.GUIMARÃES, J.L., WYPYCH, F., SAUL, C.K., RAMOS, L.P., SATYANARAYANA, K.G., Studies of the processing and characterization of corn starch and its composites with banana and sugarcane fibers from Brazil, Carbohydrate Polymers, 80, 2010, 130-138.

10.***Resoltech 1050, Hardeners $1053 \mathrm{~S}$ to $1059 \mathrm{~S}$. Structural lamination epoxy system. Available online: https://www.resoltech.com/en/markets/1050-detail.html (accesed on 19th of June 2021)

11.***ASTM D3039, Standard Test Method for Tensile Properties of Polymer Matrix Composite Materials. Available online: https://www.astm.org/Standards/D3039 (accesed on 22th of June 2021) 
12.***ASTM D695-15, Standard Test Method for Compressive Properties of Rigid Plastics. Available online: https://www.astm.org/Standards/D695-15 (accesed on 22th of June 2021)

13. BURADA C.O., MIRIŢOIU, C.M., STĂNESCU, M.M., BOLCU, D., The vibration behaviour of composite sandwich platbands reinforced with glass fiber, Romanian Journal of Materials, 45(3), 2015, 244-254.

14.NOWACKI, W., Dynamic of elastic systems, Technical Publishing House, Bucharest, 1969.

15.STĂNESCU, M.M., BOLCU, D., MANEA, I., CIUCĂ, I., BAYER, M., SEMENESCU, A., Experimental researches concerning the properties of composite materials with random distribution of reinforcement, Mater. Plast., 46(1), 2009, 73-78.

16.MIRIŢOIU, C.M., STĂNESCU, M.M., BOLCU, D., Researches regarding the mechanical properties of a new hybrid vegetal resin, Mater. Plast., 57(1), 2020, 37-45.

$\overline{\text { Manuscript received: } 01.11 .2021}$ 